\title{
OPTIMIZATION OF DESIGN AND OPERATING PARAMETERS FOR ENHANCING THE PERFORMANCES OF PEMFC WITH SERPENTINE FLOW FIELDS
}

\author{
VELMURUGAN PAVANAN ${ }^{1} \boldsymbol{\&}$ LAKSHMINARAYANAN VARADHARAJAN ${ }^{2}$ \\ ${ }^{I}$ Department of Mechanical Engineering, Malla Reddy College of Engineering, Hyderabad, Telangana, India \\ ${ }^{2}$ Department of Mechanical Engineering, B V Raju Institute of Technology, Narsapur, Telangana, India
}

\begin{abstract}
The performance of the Proton Exchange Membrane Fuel Cell (PEMFC) depends on various design and operating parameters. The present work is aimed to optimize the performance of $25 \mathrm{~cm}^{2}$ PEMFC, with respect to one design parameter (landing to channel width ratio- L: C) of serpentine flow field and two operating parameters (cell temperature \& back pressure). Here, Taguchi technique and analysis of variance methodology have been used to obtain the optimum combination for the above three parameters. The experiments have been carried out with respect to Taguchi's orthogonal array of L9 (33), for parametric analysis of PEMFC performance. Three factors and three levels, such as various landing width to channel width ratio (1:1, 1:2 and $2: 2)$, cell temperature $\left(40{ }^{\circ} \mathrm{C}, 50{ }^{\circ} \mathrm{C}\right.$ and $\left.60^{\circ} \mathrm{C}\right)$ and back pressure (0, 0.5 and 1 bar) have been taken for optimization studies. Based on the experimental study conducted on serpentine flow field, the maximum power density of $0.263 \mathrm{~W} / \mathrm{cm}^{2}$ has obtained at 1 bar back pressure, $60^{\circ} \mathrm{C}$ cell temperature and $L: C$ - 1:2. Among all the design and operating parameters, the major parameter that contributes to the performance of PEMFC is back pressure with $69.8 \%$.

KEYWORDS: Analysis of Variance, Design and Operating Parameters, Serpentine, Taguchi Technique \& Landing to Channel Width Ratio
\end{abstract}

Received: Jul 16, 2017; Accepted: Aug 08, 2017; Published: Aug 22, 2017; Paper Id: IJMPERDAUG201745

\section{INTRODUCTION}

The growing concerns on environmental issues have been constantly demanding cleaner and more energy efficient vehicles. In order to explore environment friendly alternatives, many automobile manufactures started focusing on Fuel cell powered vehicles [1]. Hence, the rapid rate of technical advances on the fuel cells, they will sooner become a viable alternative to internal combustion engine technology [2]. Fuel cells with its combination of ultra low emission and high efficiency attracts many of the fuel cell developers for rapidly commercializing this environment friendly technology [3]. It will be certainly the technology of choice of the future hydrogen economy, when our fossil fuel runs out.

Efficiency of the PEMFC is governed by various geometrical parameters such as, flow field dimensions (like width, depth, length), landing to channel width ratios (L: C), cross-sectional structure of the flow channels, type of flow field design, number of cells and number of flow passes, and various operating parameters like cell temperature, operating pressure, back pressure, mass flow rate of species, stoichiometric ratio and humidity of reactants. Manso et al. [4] studied the performance of the PEMFC by examining various geometric parameters of the flow fields such as pins, straight and serpentine channels, integrated and interdigitated channels. Also, they have studied the influence of flow direction, channel length and number of channels, baffles usage in the flow 
direction, channel shape, channel and rib widths, channel depth, height to width ratios on the performance of the PEMFC. Shimpalee et al. [5] investigated the performances of PEMFC with different gas path lengths on serpentine flow field. They numerically studied $200 \mathrm{~cm}^{2}$ PEMFC with 3, 6, 13, 26 and symmetric 26 channels serpentine flow field patterns to influence the impact of channel path length and flow patterns on PEMFC performance. They concluded that the shorter path length had provided less condensed liquid water, uniform current density distributions and less flooding effect, compared to longer path length. However, due to small differences in membrane hydration, the 13-channels design had a slight advantage over 26-channels.

Grujicic and Chittajallu [6] developed a two-dimensional electrochemical model coupled with a nonlinear constrained optimization algorithm for investigating the performances of PEMFC. The results revealed that equilibrium cathode/membrane potential difference has the largest effect on the PEMFC performance based on the statistical sensitivity analysis. Yoon et al. [7] optimized channel configurations of flow fields for gas diffusion and electric conduction of the PEMFC and concluded that the narrow rib width had the peak power cell performance. Kaytakoglu and Akyalcin [8] employed Taguchi method to determine optimum operating conditions and they showed that high operating pressure has the most significant effect on signal to noise ratio on the stack performance. Yu et al. [9] analyzed the performances of a PEMFC with various operating parameters and they showed that the interactions between operating temperature and pressure had a significant effect on the PEMFC performance. Among them, the operating pressure has the most important parameter to affect the PEMFC performance.

$\mathrm{Wu}$ and $\mathrm{Ku}[10]$ used a Taguchi methodology to obtain the optimal operating parameters for the minimum pressure drops in anode and cathode channels, and maximum electrical power of PEMFC. Liu et al. [11] optimized the dimensions of gas flow channels and ribs in PEMFC. They concluded that for achieving higher power densities, the ratio of landing width to channel width should be relatively smaller. The performance enhancement of the combined effect of operating and design parameters (operating pressure, temperature and inlet mass flow rate of reactant gases and rib to channel width ratio) of single pass serpentine and interdigitated flow channel with $25 \mathrm{~cm}^{2}$ active area of PEMFC carried out by Lakshminarayanan and Karthikeyan [12]. The results revealed that the maximum power density of interdigitated flow channel with landing to channel width 1:2 showed better performance than the serpentine flow channel with same design parameter. Bozorgnezhad et al. [13] investigated the effects of operating conditions for serpentine flow channel on the performance of the PEMFC by using Design of Experiments. Their results revealed that the high stoichiometry of reactant on cathode and low stoichiometry of reactant on an anode cause the minimum cell power. Whereas, the optimum ranges of stoichiometry of fuel and oxidants on anode and cathode leads to the best performance.

In order to clearly understand the influence of design and operating parameters on the cell performance and also to find out the best combination of the parameters for achieving maximum performance, numerous trials of experiments have to be conducted. Carrying out such large number of trials is highly difficult, time consuming and costlier. An optimization tool like Taguchi's method will be greatly useful to overcome the above challenge by effectively reducing the number of trials and cost as well. The Taguchi's orthogonal array (OA) analysis can be found elsewhere [14-15] and this method also helps in evaluating the impacts of individual control factors.

Many researchers have numerically and experimentally investigated the influence of the operating and design parameters on the performance enhancement of the PEMFC. In this work, the performance of serpentine flow field with 25 $\mathrm{cm}^{2}$ active area of PEMFC has been optimized and correlations have been developed with respect to one design parameter 
(landing to channel width ratio) and two operating parameters (cell temperature $\&$ back pressure) using Taguchi technique and analysis of variance (ANOVA) methodology, to determine the optimal and proper combination of operating and design parameters in order to ensure the maximum performance of the PEMFC.

\section{EXPERIMENTAL SETUP}

A commercial Gas Diffusion Electrode (GDE) sheet has been used for experimental analysis. A seven-layer MEA of active area of $5 \times 5 \mathrm{~cm}^{2}$ with a catalyst loading of $0.5 \mathrm{mg} / \mathrm{cm}^{2}$ on both anode and cathode is used. The Nafion 115 membrane has been sandwiched with GDE on either side by hot pressing to prepare an MEA. The performance of the cell is monitored by Biologic-FCT 50S Fuel Cell Test Station, which is capable of measuring 5 V, 50 A, and $250 \mathrm{~W}$, and this has been interfaced to a computer system using FC-Lab V.5.22 software package. The graphite plates are channeled with serpentine flow field pattern for L: C dimensions of 1:1, 1:2, and 2:2 for the active area of $25 \mathrm{~cm}^{2}$. The MEA is properly humidified to ensure that majority of the catalyst sites are activated, so as to achieve the maximum performance out of it.

\section{Orthogonal Array Analysis}

In this study, an L9 orthogonal array might be the right choice because, experiment is conducted with 3 independent variables with each variable having 3 sets of values. This array assumes that there is no interaction between any two factors. The experimental plan for serpentine flow field of $25 \mathrm{~cm} 2$ PEMFC performance with respect to three parameters (A-Back pressure, B- L: C, C-Cell temperature) and three levels. The Taguchi technique has been used to identify the optimum operating condition to obtain the maximum power density of PEMFC. The controllable and uncontrollable noise sources could affect the performance of the PEMFC. In order to reduce the uncontrollable noise effects, the experimentation have been repeated four times with same operating conditions.

The power output of the PEMFC must be maximized so, the optimization was performed for "Larger the Better" and their calculation has given below by using Eq. 1.

$$
\frac{s}{\mathbf{N}}=-10 \log \left[\left(\frac{1}{r}\right) \sum_{j=1}^{r}\left\{\frac{1}{y_{j}^{2}}\right\}\right]
$$

Where,

r $\quad$ - $\quad$ Number of trial for the levels of the noise factors

$\mathrm{Yi} \quad$ - $\quad$ Average power density

In order to achieve the maximum power density, the experiments have been performed based on the Table 1 by selecting optimum combination of parameters. The peak power density determination might not be found in proposed experimental plan shown in Table 1. The peak power performance could be found out by using the balanced characteristics of orthogonal array (OA). Hence, to predict the best combination of design and operating parameters that can deliver maximum power density, the values that make signal to noise ratio $(\mathrm{S} / \mathrm{N})$ maximum are optimum. In other words, $(\mathrm{S} / \mathrm{N})$ ratio is nothing but the ratio of controlled and uncontrolled factors and it can be calculated by using Eq.1.

\section{RESULTS AND DISCUSSIONS}

The influences of control parameters such as back pressure, L: C and cell temperature for maximizing the power density for serpentine flow field of PEMFC have been evaluated using S/N ratio response analysis. The control parameters 
with the strongest influence were determined by the differences between the maximum and minimum values of the mean of $\mathrm{S} / \mathrm{N}$ ratios. Higher the differences between the mean of $\mathrm{S} / \mathrm{N}$ ratios, the influence of control parameter is maximum. Hence, the experimentation studies have been conducted for $25 \mathrm{~cm}^{2}$ PEMFC with various serpentine flow field of L:C 1:1, $1: 2$ and 2:2, cell temperature of $40 \mathrm{oC}, 50 \mathrm{oC}$ and $60 \mathrm{oC}$ and back pressure of $0,0.5$ and 1 bar respectively, as mentioned in the experimental plan, Table 1. The experimental results for serpentine flow field with four trails and $\mathrm{S} / \mathrm{N}$ ratio response analysis is shown in Table 2.

Figure 1 (a) shows the comparison of optimized polarization and power density curves with experimental number 1,4 and 7 for various cell temperatures $\left(40{ }^{\circ} \mathrm{C}, 50{ }^{\circ} \mathrm{C}\right.$ and $\left.60{ }^{\circ} \mathrm{C}\right)$ and various back pressures $(0$ bar, 0.5 bar and 1 bar) for $\mathrm{L}: \mathrm{C}$ ratio of 1:1. The experimental average peak power performances have been determined and shown in Table 3 . The peak power density values are $0.224 \mathrm{~W} / \mathrm{cm}^{2}$ for 0 bar and $40{ }^{\circ} \mathrm{C}, 0.242 \mathrm{~W} / \mathrm{cm}^{2}$ for $0.5 \mathrm{bar}$ and $50{ }^{\circ} \mathrm{C}$ and $0.258 \mathrm{~W} / \mathrm{cm}^{2}$ for 1 bar and $60{ }^{\circ} \mathrm{C}$. The studies have also been conducted for the optimum combination of $1 \mathrm{bar}, \mathrm{L}$ : $\mathrm{C}$ of $1: 2$ and $60{ }^{\circ} \mathrm{C}$ and obtained maximum peak power density value of $0.263 \mathrm{~W} / \mathrm{cm}^{2}$. The average deviation between optimum and maximum peak power performance is $2 \%$. This could be due to increased pressure that may arise out of the factors like increased reactant concentration, improved reactant diffusion and enhanced water removal from the micro pores. Figure 1 (b) shows the comparison of optimized result with experimental number 2, 5 and 8 for various cell temperatures and various back pressures for L: $\mathrm{C}-2: 2$. The experimental average peak power performances are $0.234 \mathrm{~W} / \mathrm{cm}^{2}$ for 0 bar and $50{ }^{\circ} \mathrm{C}, 0.252$ $\mathrm{W} / \mathrm{cm}^{2}$ for 0.5 bar and $60{ }^{\circ} \mathrm{C}$ and $0.254 \mathrm{~W} / \mathrm{cm}^{2}$ for 1 bar and $40{ }^{\circ} \mathrm{C}$. The average deviation between optimum and maximum peak power performance is $3.4 \%$.

Table 1: Experimental Results for L9 Combinations for Serpentine Flow Field with Various L: C Ratios, Back Pressure and Cell Temperature

\begin{tabular}{|c|c|c|c|c|c|c|}
\hline Ex. No & $\begin{array}{c}\text { Power Density } \\
\text { for Trail } 1 \\
\left(\mathbf{Y}_{1}-\mathbf{m W} / \mathrm{cm}^{2}\right) \\
\end{array}$ & $\begin{array}{c}\text { Power Density } \\
\text { for Trail } 2 \\
\left(\mathbf{Y}_{2}-\mathbf{m W} / \mathrm{cm}^{2}\right) \\
\end{array}$ & $\begin{array}{c}\text { Power Density } \\
\text { for Trail } 3 \\
\left(\mathbf{Y}_{3}-\mathbf{m W} / \mathrm{cm}^{2}\right) \\
\end{array}$ & $\begin{array}{c}\text { Power Density } \\
\text { for Trail } 4 \\
\left(\mathbf{Y}_{4}-\mathrm{mW} / \mathrm{cm}^{2}\right) \\
\end{array}$ & $\begin{array}{c}\text { Average Power } \\
\text { Density } \\
\left(\mathbf{Y}_{\mathrm{i}}-\mathbf{m W} / \mathrm{cm}^{2}\right) \\
\end{array}$ & $\begin{array}{c}\text { S/N } \\
\text { Ratio }\end{array}$ \\
\hline 1 & 209.175 & 231.994 & 216.781 & 239.600 & 224.388 & 47.0188 \\
\hline 2 & 232.650 & 234.653 & 233.317 & 235.321 & 233.985 & 47.3838 \\
\hline 3 & 245.608 & 246.240 & 245.818 & 246.452 & 246.029 & 47.8197 \\
\hline 4 & 239.801 & 243.271 & 240.972 & 244.400 & 242.143 & 47.6814 \\
\hline 5 & 250.401 & 252.074 & 250.972 & 252.604 & 251.544 & 48.0123 \\
\hline 6 & 250.21 & 251.927 & 250.782 & 252.500 & 251.355 & 48.0058 \\
\hline 7 & 257.200 & 258.029 & 257.477 & 258.304 & 257.755 & 48.2241 \\
\hline 8 & 253.653 & 254.182 & 253.829 & 254.36 & 254.005 & 48.0968 \\
\hline 9 & 259.375 & 259.334 & 259.361 & 259.32 & 259.348 & 48.2777 \\
\hline
\end{tabular}

Figure 1 (c) shows the comparison of optimized combination results obtained with experimental numbers 3,6 and 9 for 0 bar and $60{ }^{\circ} \mathrm{C}, 0.5$ bar and $40{ }^{\circ} \mathrm{C}$, and 1 bar and $50^{\circ} \mathrm{C}$ with L:C ratio of 1:2. It has been observed from the experimental results, the average peak power performance are $0.246 \mathrm{~W} / \mathrm{cm}^{2}, 0.251 \mathrm{~W} / \mathrm{cm}^{2}$ and $0.259 \mathrm{~W} / \mathrm{cm}^{2}$ and the average peak power performance of optimum combination yields $1.5 \%$ higher than the experimental number 9 . The commercial software MINITAB 14 has been utilized for the design of experiments (DOE). The experimental results and calculated values obtained based on the plan of experiments, have been analyzed with the software. The mean effects plots for signal to noise plots have been automatically generated during the analysis. The factors are classified into signal (control factors) and noise (uncontrolled factors). In order to confirm the accuracy of results, the S/N ratios have been computed for all the factors. The obtained mean effects plots of serpentine flow field for signal to noise ratio are shown in Figure 2. 

the Performances of PEMFC with Serpentine Flow Fields

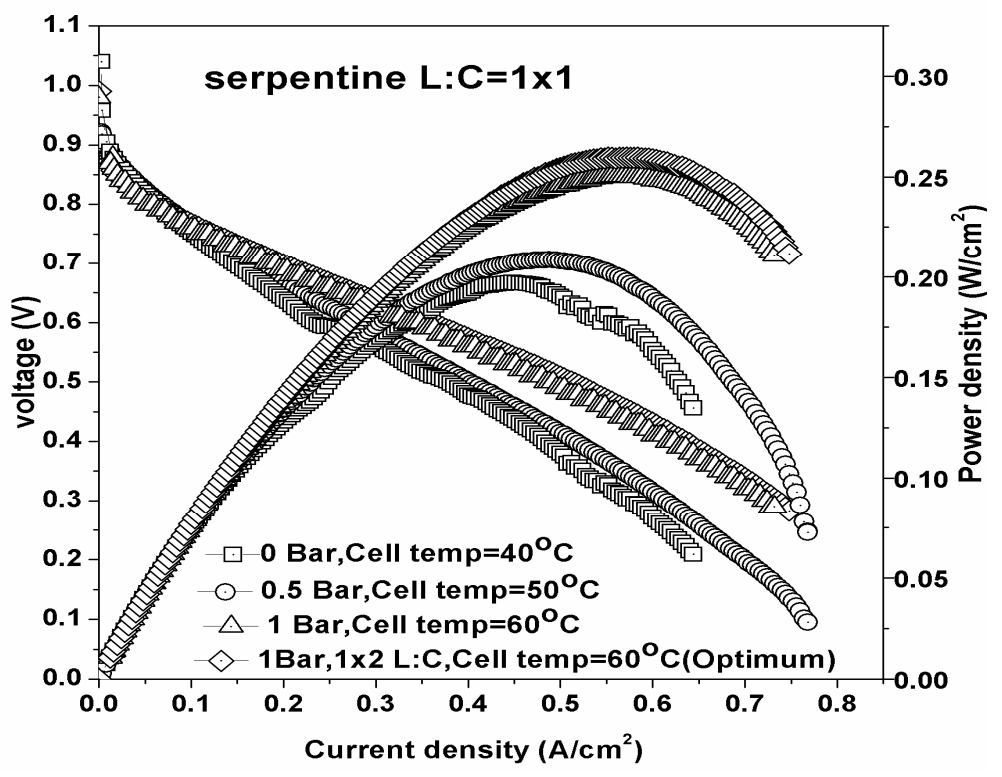

(a)

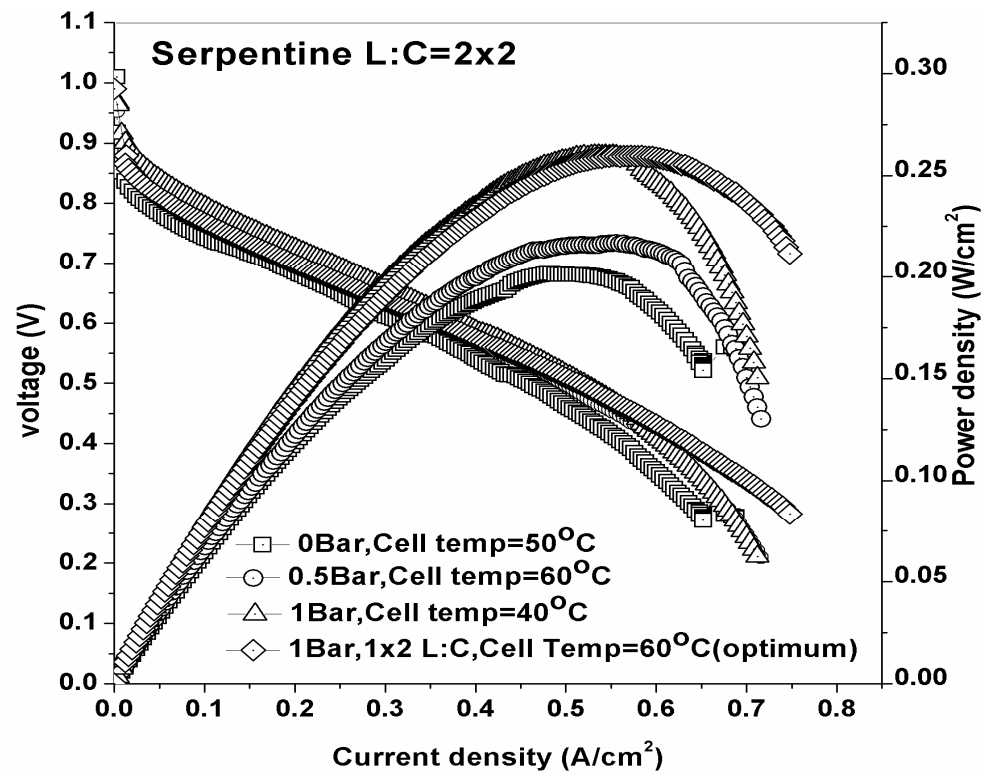

(b) 


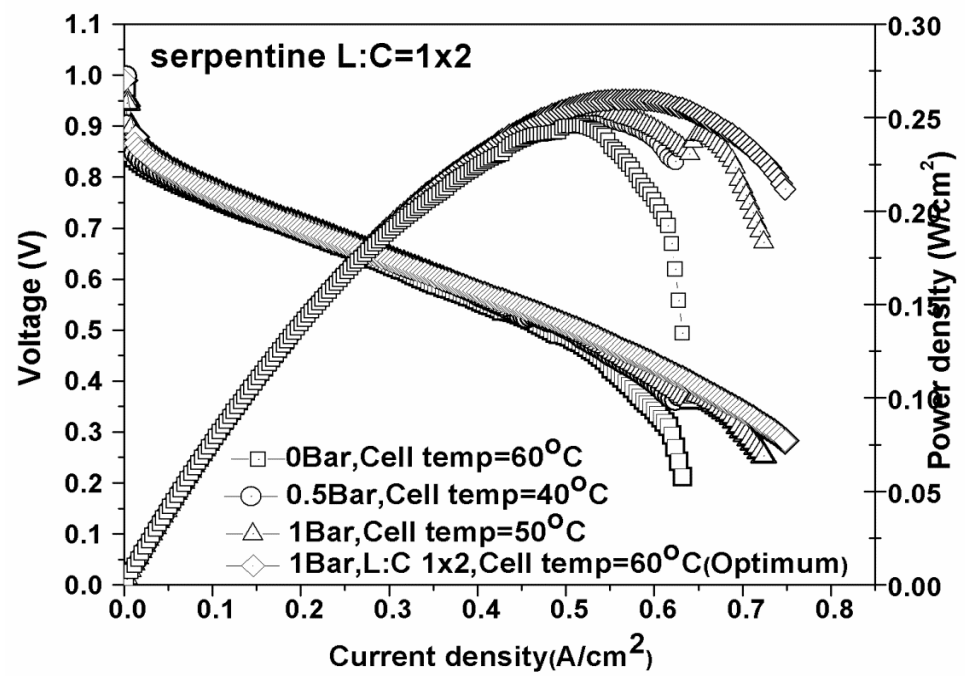

(c)

Figure 1: Polarization and Power Density Curves of Serpentine Flow Field for L: C (a) 1:1 (b) 2:2 (c) 1:2 and Optimum Combination

The level of factors at which the maximum power density is obtained for serpentine flow field should exhibit the highest $\mathrm{S} / \mathrm{N}$ ratio. It could be seen that the back pressure of 1 bar, L:C of 1:2 and the cell temperature of $60{ }^{\circ} \mathrm{C}$ (third level of all the factors) are the optimum parameters to show the better performance of PEMFC for serpentine flow field. However, these conditions have not available in the L9 orthogonal array, hence, the optimum conditions have been arrived separately and the results are given in Table 2.

Table 2: Optimum Level Process Parameters for Serpentine Flow Field

\begin{tabular}{|c|c|c|c|}
\hline Back Pressure (bar) & L:C & Temperature $\left({ }^{\circ} \mathbf{C}\right)$ & $\begin{array}{c}\text { Power Density Serpentine } \\
\text { Flow Field }\left(\mathbf{m W} / \mathbf{c m}^{2}\right)\end{array}$ \\
\hline 1 & $1: 2$ & 60 & 263.22 \\
\hline
\end{tabular}

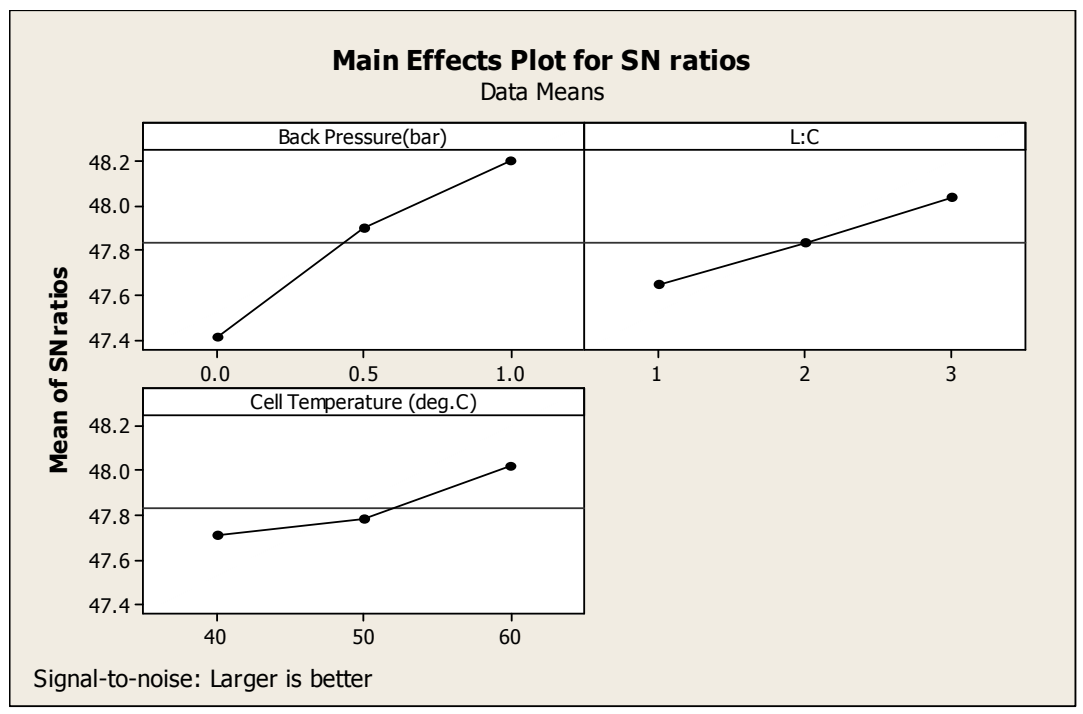

Figure 2: The Mean Effects Plot for S/N Ratios for Serpentine Flow Field

The influences of controlled process parameters such as back pressure, L: C and cell temperature have been analyzed and the significance of each factor by ranking them according to their performances are given in Table 3 . The 
difference between maximum and minimum values of $\mathrm{S} / \mathrm{N}$ ratios at each level is designated as delta and ranking is done based on magnitude of delta value. Higher the delta value indicates higher ranking.

Table 3: Response Table for Signal to Noise Ratios: Larger the Better for Serpentine Flow Field

\begin{tabular}{|c|c|c|c|}
\hline Level & Back Pressure & L:C & Cell Temperature \\
\hline 1 & 47.41 & 47.64 & 47.71 \\
\hline 2 & 47.90 & 47.83 & 47.78 \\
\hline 3 & 48.20 & 48.03 & 48.02 \\
\hline Delta & 0.79 & 0.39 & 0.31 \\
\hline Ranking & 1 & 2 & 3 \\
\hline
\end{tabular}

The results of the variance analysis for the maximum power density for serpentine flow field are shown in Table 4. It is observed from Table 4 that, in the case of serpentine flow field, the back pressure is providing $69.8 \%$ contribution to peak power performance of PEMFC. The L:C and cell temperature are providing $15.45 \%$ and $10.2 \%$, respectively, to the peak power performance. From the above mentioned results, it can be concluded that the operating parameter back pressure has a significant impact followed by L: C and cell temperature on the performance enhancement of PEMFC for serpentine flow field.

Table 4: Results of the Variance Analysis for the Maximum Power Density for Serpentine Flow Field

\begin{tabular}{|l|c|c|c|c|c|c|}
\hline Factors & Degree of Freedom & Sum of Squares & Variance & F-Test & P-Test & Contribution (\%) \\
\hline A & 2 & 753.409 & 376.704 & 61.913 & 0.01589 & 69.80 \\
\hline B & 2 & 175.671 & 87.835 & 14.436 & 0.06478 & 15.45 \\
\hline C & 2 & 120.146 & 60.073 & 9.873 & 0.09197 & 10.20 \\
\hline Error & 2 & 12.168 & 6.084 & - & - & 4.55 \\
\hline Total & $\mathbf{8}$ & $\mathbf{1 0 6 1 . 3 9 6}$ & - & - & - & $\mathbf{9 5 . 4 5}$ \\
\hline
\end{tabular}

Linear regression analysis has been employed for the present PEMFC studies. The regression equation developed for serpentine flow field to estimate the power density is;

Power density $\left(\mathrm{mW} / \mathrm{cm}^{2}\right)=203+22.2$ Back Pressure (bar) + 5.41 L: C+ 0.426 Cell temperature (deg. C)

$$
\mathrm{R}^{2}=94.7 \%
$$

From the Eqn.2, it is observed that the co-efficient associated with all parameters have positive magnitudes for serpentine flow field. Hence it clearly indicates that the back pressure is having major influence for obtaining maximum power density. L: C and the temperatures are having marginal effects for the performance enhancement of PEMFC system. The square of regression co-efficient $\left(\mathrm{R}^{2}\right)$ values obtained for the peak power density for serpentine flow field found from the above Eqn.2 could be used to predict the performances of the PEMFC. In order to validate the regression model, confirmation tests have been carried out by using a specific combination of the parameters and levels used for the analysis. The different parameter levels chosen for the confirmation test plans are shown in Table 5. Computation has been carried out after feeding the proper operating and design parameter values in Eqn.2. A comparison of experimental values and the computed values obtained from the regression model is given in Table 6 . The results clearly had shown that, the percentage deviation ranges between $0.471 \%$ and $1.156 \%$ for serpentine flow field. The maximum deviation is only $1.156 \%$ between the experimental values and the values obtained from the regression model. Hence, it is suggested from this study, that the combination of Taguchi analysis, ANOVA techniques and multiple regression analysis are essential for successfully calculating the maximum peak power density of a PEMFC. 
Table 5: Confirmation Test Plans for Serpentine Flow Field

\begin{tabular}{|c|c|c|c|}
\hline & \multicolumn{3}{|c|}{ Independent Variables } \\
\hline Experimental no. & A & B & C \\
\hline 1 & 1 & 1 & 1 \\
\hline 2 & 2 & 2 & 2 \\
\hline
\end{tabular}

Table 6: Comparison of Experimental Test Data and Regression Model for Maximum Power Density

\begin{tabular}{|c|c|c|c|}
\hline \multirow{2}{*}{ S. No } & \multicolumn{3}{|c|}{ Power Density of Serpentine Flow Field (mW/cm $\left.{ }^{2}\right)$} \\
\cline { 2 - 4 } & Experimentation & Regression Model (Eq. 2) & \% of Deviation \\
\hline 1 & 224.387 & 225.45 & 0.471 \\
\hline 2 & 249.10 & 246.22 & 1.156 \\
\hline
\end{tabular}

\section{CONCLUSIONS}

The following conclusions have been made in the present study.

Performance studies on PEMFC with serpentine flow field with various design parameter (L:C - 1:1, 1:2, 2:2) and operating parameters (cell temperature of $40{ }^{\circ} \mathrm{C}, 50{ }^{\circ} \mathrm{C}$ and $60{ }^{\circ} \mathrm{C}$ and back pressure of $0,0.5$ and 1 bar) have been carried out.

Taguchi technique and ANOVA methodology have been used to obtain the optimum combination and their contributions to the PEMFC performance. The design parameter L: C of 1:2 and the operating parameters, back pressure of $1 \mathrm{bar}$, and cell temperature of $60{ }^{\circ} \mathrm{C}$ have produced maximum power densities of $0.263 \mathrm{~W} / \mathrm{cm}^{2}$ for serpentine flow fields.

Also, the F and P tests carried out in this study indicated that the back pressure is having major influence on the peak power performance of PEMFC. The back pressure is providing $69.8 \%$ contribution to the peak power density for serpentine flow field. The L:C and cell temperatures are providing $15.45 \%$ and $10.2 \%$, respectively, for serpentine flow filed.

The multiple linear regression analysis indicated the same $\mathrm{R}^{2}$ value $(94.7 \%)$ for serpentine flow field with allowable maximum deviation limit $5.3 \%$. Also, the results clearly show that, the percentage deviation ranges between $0.471 \%$ and $1.156 \%$ for serpentine flow field. The maximum deviation is only $1.156 \%$ between the experimental values and the values obtained from the regression model.

\section{REFERENCES}

1. Woong-chul Yang, Bradford Bates, Nicholas Flecther, Ric Pow, 1998, Control Challenges and Methodologies in Fuel Cell Vehicle Development, Proceedings of the 1998 International Congress on Transportation Electronics; 363-370.

2. Venki Raman, 'The Hydrogen Fuel Option for Fuel Cell Vehicle Fleets'. Society of Automotive Engineers Technical Paper 1999-01-0529.

3. Mark Allard, 'Issues Associated with Widespread Utilization of Methanol'. Society of Automotive Engineers Technical Paper 2000-01-0005.

4. Manso. AP, Marzo. FF, Barranco. J, Garikano. X, Garmendia, Mujika. M 2012, Influence of geometric parameters of the flow fields on the performance of a PEM fuel cell - A Review, International Journal of Hydrogen Energy, vol.37, no.20, pp.1525615287.

5. Shimpalee, S, Greenway, S \& Van Zee, J 2006, The impact of channel path length on PEMFC flow-field design, Journal of Power Sources, vol. 160, no. 1, pp. 398-406. 
6. Grujicic, M \& Chittajallu, K 2004, Design and optimization of polymer electrolyte membrane (PEM) fuel cells, applied surface science, vol. 227, no. 1, pp. 56-72.

7. Yoon, Y-G, Lee, W-Y, Park, G-G, Yang, T-H \& Kim, C-S 2005, Effects of channel and rib widths of flow field plates on the performance of a PEMFC, International journal of hydrogen energy, vol. 30, no. 12, pp. 1363-1366.

8. Kaytakoğlu, S \& Akyalçın, L 2007, Optimization of parametric performance of a PEMFC, International journal of hydrogen energy, vol. 32, no. 17, pp. 4418-4423.

9. $Y u, W-L, W u, S-J \&$ Shiah, S-W 2008, Parametric analysis of the proton exchange membrane fuel cell performance using design of experiments, International journal of hydrogen energy, vol. 33, no. 9, pp. 2311-2322.

10. Wu, $\mathrm{H}-\mathrm{W} \& \mathrm{Ku}, \mathrm{H}-\mathrm{W} 2012$, Effects of modified flow field on optimal parameters estimation and cell performance of a PEM fuel cell with the Taguchi method, International journal of hydrogen energy, vol. 37, no. 2, pp. 1613-1627.

11. Hong Liu, Peiwen Li, Kai Wang, 2013, Optimization of PEM fuel cell flow channel dimensions - Mathematic modeling analysis and experimental verification'. International journal of hydrogen energy, 38:9835 - 9846.

12. Lakshminarayanan V\& Karthikeyan P, 2016, Optimization of Flow Channel Design and Operating Parameters on Proton Exchange Membrane Fuel Cell Using Mat lab. Periodica Polytechnica Chemical Engineering. Budapest Univ Technology Economics, 60, 3; 173-180.

13. Bozorgnezhad, A, Shams, M, Kanani, H, Hasheminasab, $M \&$ Ahmadi, G 2015, The experimental study of water management in the cathode channel of single-serpentine transparent proton exchange membrane fuel cell by direct visualization, International journal of hydrogen energy, vol. 40, no. 6, pp. 2808-2832.

14. Roy RK. Design of experiments using the Taguchi approach. New York: Wiley; 2001.

15. Logothetis N, Wynn HP. Quality through design. Oxford: Clarendon Press; 1989. 
